\title{
Identidade e qualidade de sardinhas em conserva comercializadas em Aracaju, estado de Sergipe
}

\section{Identity and quality of canned sardines marketed in Aracaju, Sergipe State}

\author{
Adriano Fernandes Ferreira*, José Milton Barbosa \& Anderson de Almeida Santos \\ Departamento de Engenharia de Pesca e Aquicultura, Universidade Federal de Sergipe - UFS. \\ *E-mail: adrifernanfer@gmail.com
}

Recebido: 19 de setembro de 2017 / Aceito: 21 de outubro de 2017 / Publicado: 17 de dezembro de 2017

Resumo O presente estudo teve como objetivo avaliar a qualidade de sardinhas em conserva comercializadas na cidade de Aracaju, estado de Sergipe, em função da legislação vigente. Foram analisadas 50 amostras de sardinhas em conserva (latas de 125g), em óleo e em molho de tomate, adquiridas em supermercados da região, pertencentes às seguintes marcas nacionais: Pescador, 88, Robinson Crusoe, Gomes da Costa e Coqueiro. As amostras em óleo comestível foram classificadas aleatoriamente como A1, B1, C1, D1 e $\mathrm{E} 1$, e as amostras correspondentes em molho de tomate foram classificadas como A2, B2, C2, D2 e $\mathrm{E} 2$. Os principais problemas encontrados foram latas com amassamento e pontos de oxidação na parte externa, peixes com escamas soltas, mutilações, presença de vísceras no interior dos animais e pesos abaixo ou acima do declarado. Da análise sensorial, verificou-se que entre as sardinhas em óleo, a marca que teve o melhor índice de aceitabilidade, foi a E1 (75\% de qualificação boa e muito boa), seguida da marca D1 que pelo teste de análise de variância, apresentou características sensoriais semelhantes da marca E1. Por outro lado, a marca B1 foi que apresentou o menor índice de aceitabilidade. Já entre as sardinhas em molho de tomate, de modo geral, verificou-se um índice de aceitabilidade mais homogêneo, com destaque para a marca C2 com $71 \%$ de aceitação. Conclui-se que, apesar de serem encontrados defeitos, quando da aplicação do Regulamento Técnico de Identidade e Qualidade de Conservas de Sardinhas, de modo geral, as sardinhas analisadas podem ser consideradas de boa qualidade e adequadas para o consumo.

Palavras-chave: enlatado, embalagem, peso líquido, análise sensorial.
Abstract The present study aimed to evaluate the quality of canned sardines sold in the city of Aracaju, Sergipe, according to the current legislation. There were 50 samples analyzed of canned sardines $(125 \mathrm{~g}$ cans), in oil and tomato sauce, purchased in supermarkets in the region, belonging to the following national brands: Pescador, 88, Robinson Crusoe, Gomes da Costa and Coqueiro. The samples of edible oil were classified randomly as A1, B1, C1, $\mathrm{D} 1, \mathrm{E} 1$, and the corresponding samples in tomato sauce were classified as A2, B2, C2, D2 and E2. The main problems found were cans with kneading and oxidation points on the outside, fish with scales, mutilations, presence of viscera inside of animals and weights below or above the declared. From sensory analysis, it was found that among the sardines in oil, the brand that had the best index of acceptability was the E1 (75\% of qualifying good and very good), then D1 brand by variance analysis test, presented similar sensory characteristics of the E1 brand. On the other hand, the B1 brand was presented the lowest index of acceptability. Among the sardines in tomato sauce, there has been a more homogeneous accessibility index, especially by the brand with $71 \% \mathrm{C} 2$ acceptance. It is concluded that, despite the defects found, when the application of the identity technical regulation and quality of canned Sardines, the analyzed sardines can be generally considered of good quality and suitable for consumption.

Keywords: canned, packing, net weight, sensory analysis. 


\section{Introdução}

O crescimento da população mundial e a busca por alimentos de melhor qualidade coloca o pescado numa posição de destaque como fonte alimentar, seja pelos diversos benefícios provenientes do seu consumo como fonte de minerais, proteína de boa qualidade, Omega3 e baixo teor de colesterol, bem como por seu grande potencial de maximização produtiva decorrente do desenvolvimento de novas tecnologias em atividades como o gerenciamento dos estoques pesqueiros, o aproveitamento integral do pescado e a aquicultura (Lima, Dell'Isola \& Schettin, 2000).

A rápida deterioração decorrente de fatores microbiológicos torna o pescado um dos alimentos mais perecíveis, sendo de extrema importância os cuidados necessários ao seu manuseio em todas as etapas da sua cadeia produtiva, ou seja, desde que é capturado fresco até chegar ao consumidor após a passagem pela indústria transformadora (Gonçalves, 2004).

É importante salientar que o beneficiamento/processamento do pescado é um elo importante da cadeia produtiva, pois além de poder propiciar o aproveitamento integral do pescado, agrega valor ao produto tornando-o diferenciando e competitivo por oferecer novas opções ao consumidor que cada vez mais é exigente. Possibilitando, ainda, a comercialização do produto de forma higiênica, com maior tempo de prateleira, bem como, a geração empregos diversos (Lima, Dell'Isola \& Schettin, 2000).

Dentre os diversos tipos de beneficiamento/processamento de pescado podemos destacar o enlatamento da matéria-prima, especialmente para espécies formadoras de grandes cardumes, como as sardinhas e os atuns. Sendo um método de conservação com elevado reconhecimento e valorização tanto por parte da indústria alimentar como do público consumidor (Aubourg, 2001), por ter como objetivos principais, a preparação de um produto de boa qualidade capaz de ser armazenado durante um tempo razoável, ser de fácil preparo, ser transportado facilmente e não necessitar de refrigeração. No entanto, a qualidade da conserva depende não só das condições de processo, mas também da matéria-prima utilizada (Gonçalves, 2004).

As sardinhas estão inseridas na família Clupeidae, que se caracterizam por serem peixes de pequeno porte e de corpo lateralmente comprimido e prateado. Formam cardumes e habitam águas costeiras (Figueiredo \& Menezes, 1978). No Brasil, a espécie de sardinha mais importante é a Sardinella brasiliensis, que habita apenas na costa brasileira. Além dela, duas espécies importadas podem ser enlatadas com esse nome: Sardinella aurita e Sardina pilchardus (Barbosa, Queiroz, Santos, Mendes \& Leitão, 2006). De acordo com as normas do Codex, a utilização de outras espécies no enlatamento de sardinhas se configura em fraude.

Conservas de sardinhas são produtos elaborados a partir de matéria-prima fresca ou congelada, descabeçada, eviscerada (com exceção de gônadas e rins), acrescidos de meio de cobertura, acondicionados em um recipiente hermeticamente fechado e que tenham sido submetidos a um tratamento térmico que garanta sua esterilidade comercial (Brasil, 2011a). A esterilidade comercial, refere-se a um tratamento térmico que destrói os microrganismos patogênicos e deterioradores que possam crescer sob condições normais de estocagem (Vasconcelos \& Melo Filho, 2010).

Todo esse esforço no sentido de oferecer um produto pronto para ser consumido, de boa qualidade e economicamente acessível, só se justifica se for verdadeiramente aceito pelo consumidor. Daí a importância da análise sensorial, que segundo Ogawa (1999), é o único meio de avaliação de que o consumidor dispõe, permitindo responder a perguntas sobre a qualidade do produto, no que diz respeito à discriminação, descrição ou preferência, incluindo sua aceitação ou rejeição. Sendo, portanto, crucial no processo de desenvolvimento ou melhoramento de produtos.

Diante da importância do consumo do pescado enlatado e da influência do processamento nos padrões esperados para a sua comercialização, fica evidente a necessidade de verificações frequentes do controle de qualidade adotado pelas fábricas de conservas de pescado, no sentido de se evitar o risco de contaminação e a venda do pescado em conserva de maneira inapropriada ou fraudulenta (Diniz, Barbosa\& Santos, 2014).

Neste contexto, o presente trabalho teve como objetivo avaliar o a qualidade sensorial do enlatamento e a aceitabilidade de sardinhas em conserva mais comuns comercializadas na cidade de Aracaju, Estado de Sergipe, em função da legislação vigente.

\section{Material e métodos}

Foram analisadas 50 amostras (latas) de sardinhas em conserva, de 125g, adquiridas em supermercados de Aracaju - SE, pertencentes a cinco marcas fabricação nacional que dispunham dos tipos óleo comestível e molho de tomate. Para cada marca foram analisadas 10 amostras, sendo 5 em óleo comestível e 5 em molho de tomate. As marcas foram codificadas aleatoriamente como marca A, B, C, D e E, sendo tipo 1 para óleo 
comestível e tipo 2 para molho de tomate, ficando a classificação da seguinte forma: A1, B1, C1, D1 e E1 para as amostras em óleo comestível e A2, B2, C2, D2 e E2 para as amostras em molho de tomate.

A escolha dos produtos foi baseada no levantamento das marcas disponíveis em diversos supermercados da cidade que dispunham dos dois tipos de meio de cobertura escolhidos para a pesquisa.

As latas de sardinha foram observadas externamente, abertas, drenadas e o produto pesado. Os itens avaliados foram: Embalagem (EMB); Rotulagem (ROT); Quantidade de peixes por lata (n); Apresentação visual do produto (APP); Peso drenado (PD); Peso líquido (PL); Análise visual do meio de cobertura (MC) e Qualidade da carne (QC).

Os itens EMB, n, APP, MC E QC foram comparados com os padrões estabelecidos pela Instrução Normativa SDA no 22 , de 11 de julho de 2011, que fixa a identidade e as características mínimas de qualidade que deve apresentar o produto conservas de sardinhas para a sua comercialização, RTIQ-Sardinhas, e com os padrões exigidos pela Norma do Codex para as sardinhas e produtos análogos em conserva (Codex Stan 94, 1981). A rotulagem (ROT) foi avaliada com base na Instrução Normativa $\mathrm{n}^{\mathrm{o}} 22$, de 24 de novembro de 2005, que dispõe sobre o Regulamento Técnico para Rotulagem de Produto de Origem Animal Embalado.

Seguindo as normas do Regulamento Técnico Metrológico - metodologia para determinação do peso drenado para os produtos pré-medidos, Portaria Inmetro $\mathrm{n}^{-}$231, de 19 de setembro de 2000, procedeu-se a abertura das latas escorrendo líquido de cobertura em uma peneira durante 2 min para um recipiente previamente tarado. Através de uma balança semi-analítica, foi realizado a pesagem dos conteúdos sólidos (peso drenado, sem o líquido de cobertura) e do conteúdo líquido (peso do líquido de cobertura), que foram somados para se obter o peso líquido medido (peso total sem o peso da lata) de cada marca, cujas médias foram comparadas com o descrito na embalagem.

Com o objetivo de se verificar a existência de diferença estatisticamente significativa entre as médias dos pesos drenados observados (PD) e os pesos drenados indicados na embalagem do produto, cada tipo de amostra foi submetida a análise de variância - Anova de fator único.

A análise sensorial foi realizada com o objetivo de se verificar o grau de aceitação das amostras de conservas de sardinhas junto a potenciais consumidores, utilizando-se fichas de avaliação, modelo em anexo, de escala hedônica de cinco pontos $(1=$ ruim e $5=$ muito bom $)$, aplicada aos cinco atributos sensoriais que, segundo o RTIQ, devem apresentar características próprias: aparência, cor, odor, sabor e textura. Os produtos foram avaliados por 10 julgadores não treinados, potencialmente consumidores, composto por acadêmicos e servidores universitários, sendo sete pessoas do gênero feminino e três do gênero masculino. Para que os julgadores não soubessem as marcas das conservas de sardinha que estavam sendo consumidas, as amostras de conservas em óleo foram previamente codificadas como A1, B1, C1, D1 e E1, e as amostras correspondentes de conservas em molho de tomate com os códigos A2, B2, C2, D2 e E2. As porções de aproximadamente 15g foram servidas em pratos descartáveis e os graus de aceitação foram marcados nas fichas de avaliação sensorial distribuída aos degustadores. A cada troca de amostra era oferecido uma bolacha água e sal para neutralizar o sabor das papilas gustativas.

A partir das fichas respostas preenchidas foi possível avaliar o índice de aceitabilidade das diferentes marcas, tomando por base a porcentagem de ocorrência das pontuações de aceitação positiva $(4=$ boa e $5=$ muito boa) nos diversos atributos sensoriais avaliados. De posse do índice de aceitabilidade, procedeu-se o teste de variância, Anova, complementado pelo teste de Tukey entre as médias dos pares de amostras, como o objetivo de verificar a existência de diferença significativamente estatística entre as marcas mais aceitas e mais rejeitadas pelos degustadores.

\section{Resultados e discussão}

De acordo com Barbosa et al. (2006), os padrões esperados para que as sardinhas em conservas sejam consideradas de boa qualidade, devem seguir as instruções contidas no Regulamento Técnico de Identidade e Qualidade de Conservas de Sardinhas - RTIQ (cuja versão mais atualizada consta na Instrução Normativa SDA $\mathrm{n}^{\mathrm{o}} 22$, de 11 de julho de 2011) e na Norma do Codex para as sardinhas e produtos análogos em conserva (Codex Stan 94, 1981).

Os principais pontos das normas acima citadas sugerem que as latas adequadamente rotuladas, contenham no mínimo dois peixes de mesma espécie, descabeçados, eviscerados e com tamanhos semelhantes, sem mutilações, sem presença de nadadeiras caudal e excesso de escamas soltas, e sem restos de vísceras, com exceção de gônadas e rins. Que a carne, devendo constituir, no mínimo, 50\% (cinquenta por cento) em relação ao peso líquido declarado, seja clara ou rosada, de consistência pouco fibrosa e não flácida, textura firme e que 
não apresente odor desagradável indicativo de sinais de decomposição ou rancificação. Essas características foram analisadas por Barbosa et al. (2006) e por Diniz et al. (2014).

\section{ANÁLISE DE EMBALAGENS (EMB) E ROTULAGEM (ROT)}

A tabela 1 mostra uma visão geral dos defeitos observados para o item EMB das amostras analisadas.

Tabela 1. Porcentagem de amostras de sardinhas em conserva com inconformidades nas embalagens, comercializadas na cidade de Aracaju, Estado de Sergipe, 2016.

\begin{tabular}{|c|c|c|c|c|c|c|c|c|c|c|}
\hline \multirow{2}{*}{ Defeitos de embalagem } & \multicolumn{5}{|c|}{ Marcas em óleo comestível } & \multicolumn{5}{|c|}{ Marcas em molho de tomate } \\
\hline & A1 & B1 & $\mathrm{C} 1$ & D1 & E1 & A2 & B2 & $\mathrm{C} 2$ & D2 & E2 \\
\hline Estufada & - & - & - & - & - & - & - & - & - & - \\
\hline Perfuração / Vazamento & - & - & - & - & - & - & - & - & - & - \\
\hline Ferrugem & $20 \%$ & - & - & - & - & - & - & - & - & - \\
\hline Amassada & $20 \%$ & - & $20 \%$ & - & - & $20 \%$ & - & - & - & - \\
\hline Defeito de recravação & - & - & - & - & - & - & - & - & - & - \\
\hline Defeito de verniz & - & - & - & - & - & - & - & - & - & - \\
\hline Defeito de litografia & - & - & $60 \%$ & - & - & - & - & $80 \%$ & - & - \\
\hline
\end{tabular}

Foi observado uma amostra da marca A1 com pontos de ferrugem (Figura 1), demonstrando inconformidade com a legislação, tendo em vista que o produto tem validade de quatro anos. Algumas latas também apresentaram amassamentos, que provavelmente pode ter acontecido no manuseio do produto após a saída das fábricas.

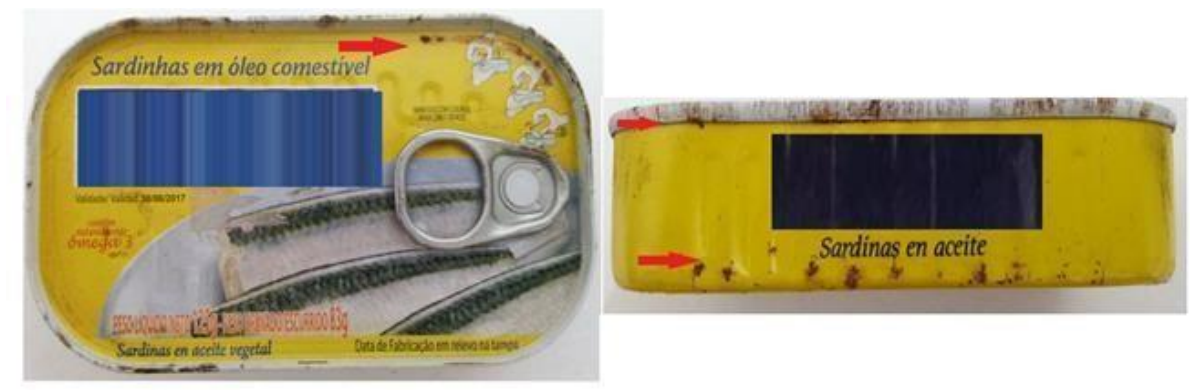

Figura 1. Embalagem com pontos de oxidação (Amostra A1) de sardinhas em conserva comercializadas na cidade de Aracaju, estado de Sergipe.

Num dos supermercados visitados, observou-se que na prateleira havia alguns exemplares da marca A1amassadas e com vazamento e perfurações (Figura 2), sendo, portanto, impróprias para o consumo, conforme previsto no o art. 386 do Riispoa que diz que serão consideradas impróprias para consumo as conservas que apresentarem: falhas de estanhagem, ferrugem, amassamentos e/ou orifícios na lata.

Devido ao avançado grau de deterioração e a total inconformidade com a tabela de defeitos constante do Anexo II do RTIQ, tais exemplares não foram avaliados. Como tal situação não foi observada em outros estabelecimentos comerciais que vendiam produtos do mesmo lote desta marca, acredita-se que este problema decorre de falhas de transporte e/ou armazenamento do próprio estabelecimento.
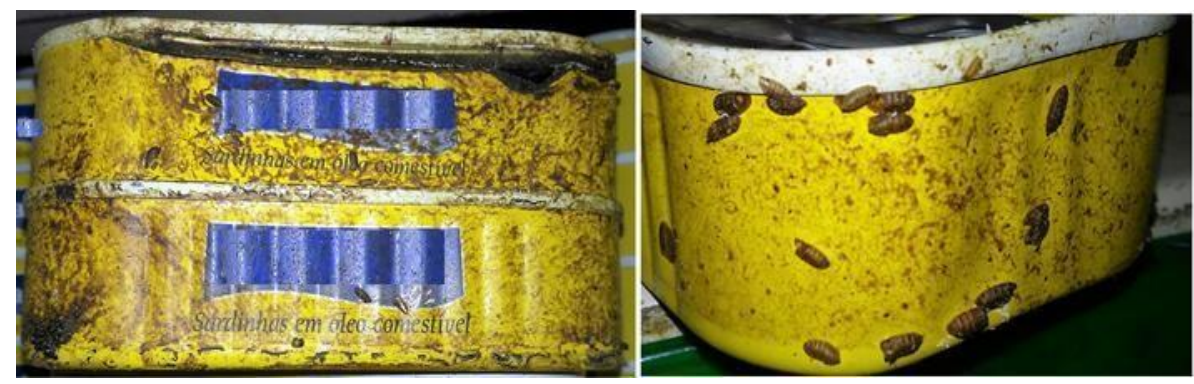

Figura 2. Exemplares da marca A1 de sardinhas em conserva com falhas de amassamentos e vazamento em estado avançado de deterioração, comercializadas na cidade de Aracaju, estado de Sergipe. 
Quanto ao item ROT foi observado que a marca A1 foi a única que não continha impresso o número do lote, porém tal fato não contraria o Regulamento Técnico para Rotulagem de Alimentos Embalados, uma vez que para indicação do lote, pode ser utilizado a data de fabricação, embalagem ou de prazo de validade, sempre que a(s) mesma(s) indique(m), pelo menos, o dia e o mês ou o mês e o ano. Já a marca C1 apresentou duas amostras com falha de impressão da validade na superfície da lata do produto (Figura 3), que, apesar da dificuldade de leitura, não ficou totalmente ilegível, mesmo assim, por não estarem impressas de forma clara e precisa, tais amostras estão em desacordo com a legislação.

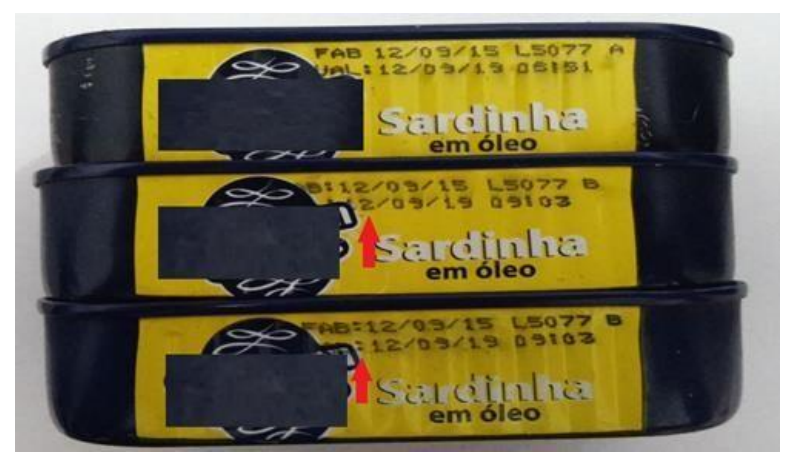

Figura 3. Rotulagem com falha de impressão (Amostra C1) de sardinhas em conserva comercializadas na cidade de Aracaju, estado de Sergipe.

A tabela abaixo mostra uma visão geral das inconformidades de rotulagem observadas nas marcas analisadas.

Tabela 2. Porcentagem das amostras de sardinhas em conserva que apresentaram inconformidades na rotulagem, comercializadas na cidade de Aracaju, estado de Sergipe.

\begin{tabular}{|c|c|c|c|c|c|c|c|c|c|c|}
\hline \multirow{2}{*}{ Defeitos de rotulagem } & \multicolumn{5}{|c|}{ Marcas em óleo comestível } & \multicolumn{5}{|c|}{ Marcas em molho de tomate } \\
\hline & A1 & $\mathrm{B} 1$ & $\mathrm{C} 1$ & D1 & E1 & $\mathrm{A} 2$ & $\mathrm{~B} 2$ & $\mathrm{C} 2$ & $\mathrm{D} 2$ & E2 \\
\hline Nome verdadeiro do produto & - & - & - & - & - & - & - & - & - & - \\
\hline Nome comum da espécie & - & - & - & - & - & - & - & - & - & - \\
\hline Meio de cobertura & - & - & - & - & - & - & - & - & - & - \\
\hline Nome da firma responsável & - & - & - & - & - & - & - & - & - & - \\
\hline Localização do estabelecimento & - & - & - & - & - & - & - & - & - & - \\
\hline Carimbo da Inspeção Federal & - & - & - & - & - & - & - & - & - & - \\
\hline Data de fabricação e validade & - & - & - & - & - & - & - & - & - & - \\
\hline Marca comercial & - & - & - & - & - & - & - & - & - & - \\
\hline Peso líquido & - & - & - & - & - & - & - & - & - & - \\
\hline Peso bruto (drenado) & - & - & - & - & - & - & - & - & - & - \\
\hline Lista de ingredientes & - & - & - & - & - & - & - & - & - & - \\
\hline Especificação "Indústria Brasileira" & - & - & - & - & - & - & - & - & - & - \\
\hline Informações nutricionais & - & - & - & - & - & - & - & - & - & - \\
\hline Número de lote & $100 \%$ & - & - & - & - & $100 \%$ & - & - & - & - \\
\hline Falha na impressão & - & - & $40 \%$ & - & - & - & - & - & - & - \\
\hline
\end{tabular}

\section{ANÁLISES DA APRESENTAÇÃo VISUAL DO PRODUTO (APP)}

$\mathrm{Na}$ análise do interior das latas, de um modo geral, foram observadas algumas inconformidades, que estão descriminadas na Tabela 3.

Foi constatado que, das latas analisadas, a marca do tipo B1 foi a que mais apresentou exemplares de peixes com a aparência ruim (Figura 4), fator esse que pesou negativamente no teste de avaliação sensorial. 
Tabela 3. Porcentagem de inconformidades observadas no interior das latas de sardinhas em conserva comercializadas na cidade de Aracaju, estado de Sergipe.

\begin{tabular}{|c|c|c|c|c|c|c|c|c|c|c|}
\hline \multirow[t]{2}{*}{ Defeitos apresentação no produto (\%) } & \multicolumn{5}{|c|}{ Marcas em óleo comestível } & \multicolumn{5}{|c|}{ Marcas em molho de tomate } \\
\hline & A1 & $\mathrm{B} 1$ & $\mathrm{C} 1$ & D1 & E1 & A2 & $\mathrm{B} 2$ & $\mathrm{C} 2$ & $\mathrm{D} 2$ & E2 \\
\hline Aparência do produto ruim ou regular & - & 80 & - & - & 60 & - & - & - & - & 20 \\
\hline № de peixes menor que 2 ou maior que 5 & - & - & - & - & - & - & - & - & - & - \\
\hline Espécie em desacordo com a rotulagem & - & - & - & - & - & - & - & - & - & - \\
\hline Excesso de escamas soltas no fundo da lata & 80 & 100 & - & 100 & 100 & 100 & 80 & 100 & 100 & 80 \\
\hline Material estranho no interior da lata & - & - & - & - & - & - & - & - & - & - \\
\hline Odor diferenciado & - & - & - & 20 & - & - & - & - & - & - \\
\hline Resto de vísceras & 80 & 100 & 20 & 40 & - & 60 & 40 & - & 80 & 40 \\
\hline Presença de ovas fragmentadas & 60 & 60 & 20 & 20 & 20 & - & 20 & - & 80 & - \\
\hline Mutilações & 20 & - & 20 & 20 & 20 & - & 60 & - & 20 & - \\
\hline Peixes com tamanhos não uniformes & 20 & - & - & 40 & 20 & 20 & 60 & - & 20 & 80 \\
\hline Verniz interno desprendido & - & - & - & - & - & - & - & - & - & - \\
\hline Alteração da cor & - & - & - & - & - & - & - & - & - & - \\
\hline \multicolumn{11}{|l|}{ Musculatura flácida, dura ou fibrosa } \\
\hline Meio de cobertura claro & - & - & - & - & - & - & - & - & - & - \\
\hline Aparência do produto ruim ou regular & - & 80 & - & - & 60 & - & - & - & - & 20 \\
\hline
\end{tabular}

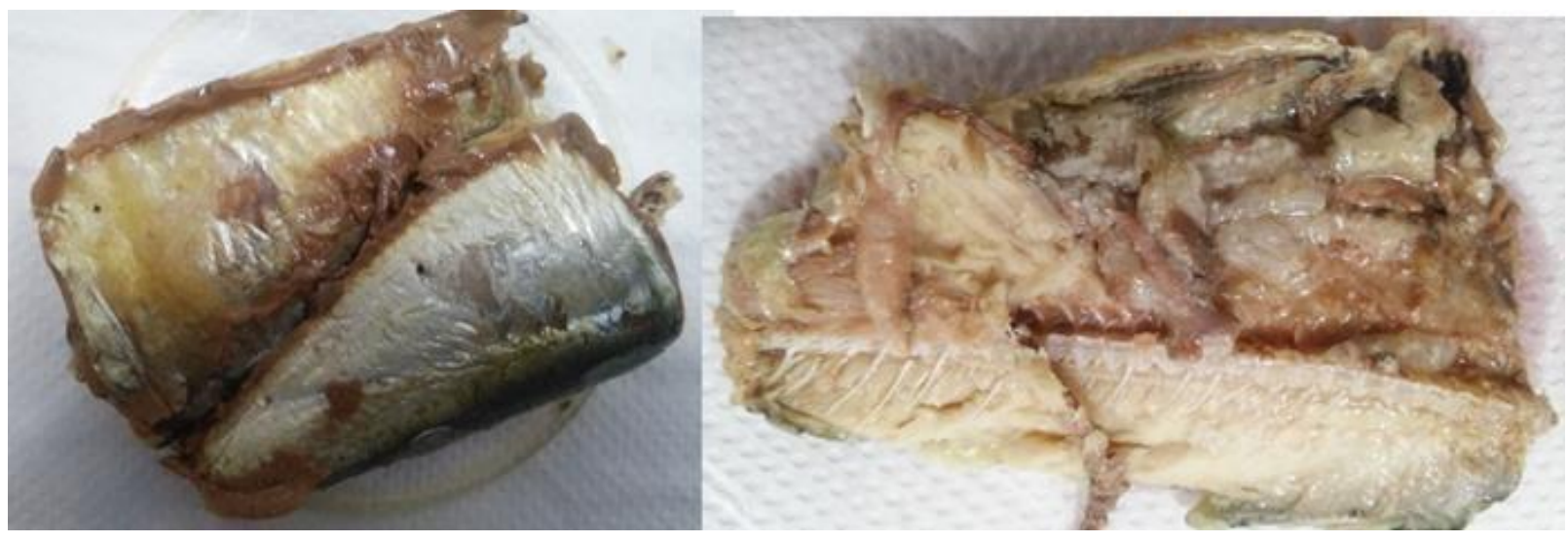

Figura 4. Exemplares de peixes com aparência ruim (Amostra B1) de sardinhas em conserva comercializadas na cidade de Aracaju, estado de Sergipe.

$\mathrm{A}$ marca $\mathrm{C} 1$ foi a única que não teve presença de escamas soltas e restos de vísceras, o que sugere um cuidado maior na evisceração e na lavagem das sardinhas para o enlatamento, sendo observado apenas a presença de gônadas e rins, o que é devidamente permitido pelo RTIQ.

Para as sardinhas em óleo, as marcas A1 e B1 apresentaram mais da metade das amostras com excessos de escamas soltas, restos de vísceras e tubo fecal. Tais problemas também foram observados nas marcas A2 e D2 das sardinhas em molho de tomate (Figura 5). 

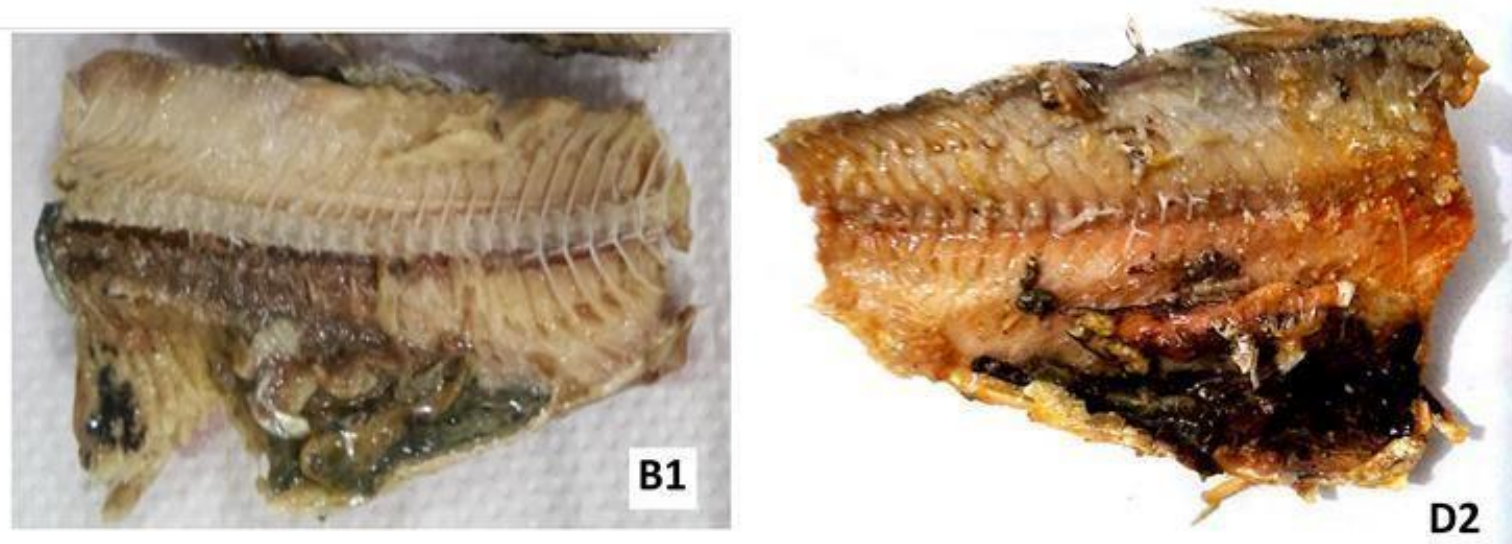

Figura 5. Exemplares de sardinhas em conserva com restos de vísceras (Amostra B1 e D2) comercializadas na cidade de Aracaju, estado de Sergipe.

Estas evidências mostram que a falta de cuidado na evisceração e lavagem do produto não é uma falha exclusiva de uma determinada marca em específico, demonstrando a real necessidade de uma ação mais efetiva dos órgãos fiscalizadores no intuito de exigir um melhor controle de qualidade por parte das fábricas de conservas de pescado. Resultados semelhantes foram também observados por Diniz et al. (2014) ao avaliarem a qualidade de sardinhas em conserva comercializadas em São Luís - MA, encontrando resquícios de vísceras em parte das amostras, estando o produto em desacordo com o RTIQ, que determina que as sardinha em conserva devem ser descabeçada e eviscerada, com exceção de gônadas e rins, e sem excesso de escamas soltas no fundo da lata.

Quanto à quantidade de peixes, a grande maioria apresentou dois peixes embalados, que é a quantidade mínima de peixes por lata exigida na Norma do Codex para as sardinhas e produtos análogos em conserva, (Codex Stan 94, 1981), e apenas as marcas em óleo C1 e E1 apresentaram amostras com três sardinhas, sendo que, segundo o RTIQ, a quantidade máxima é de cinco sardinhas por lata.

Algumas das amostras da marca $\mathrm{C} 1$ também apresentaram sinais de mutilações, que provavelmente devem ter acontecido devido à dificuldade de acondicionamento de três peixes na mesma lata. Amostras das marcas D1 e D2 também apresentaram sardinhas com mutilações, que por outro lado, pode ter ocorrido devido ao maior tamanho dos peixes enlatados. Contudo, estas mutilações estão em desacordo com as regras do RTIQ que desaprova tais defeitos de processamento, além de influenciarem negativamente na aceitação do produto (Figura 6).
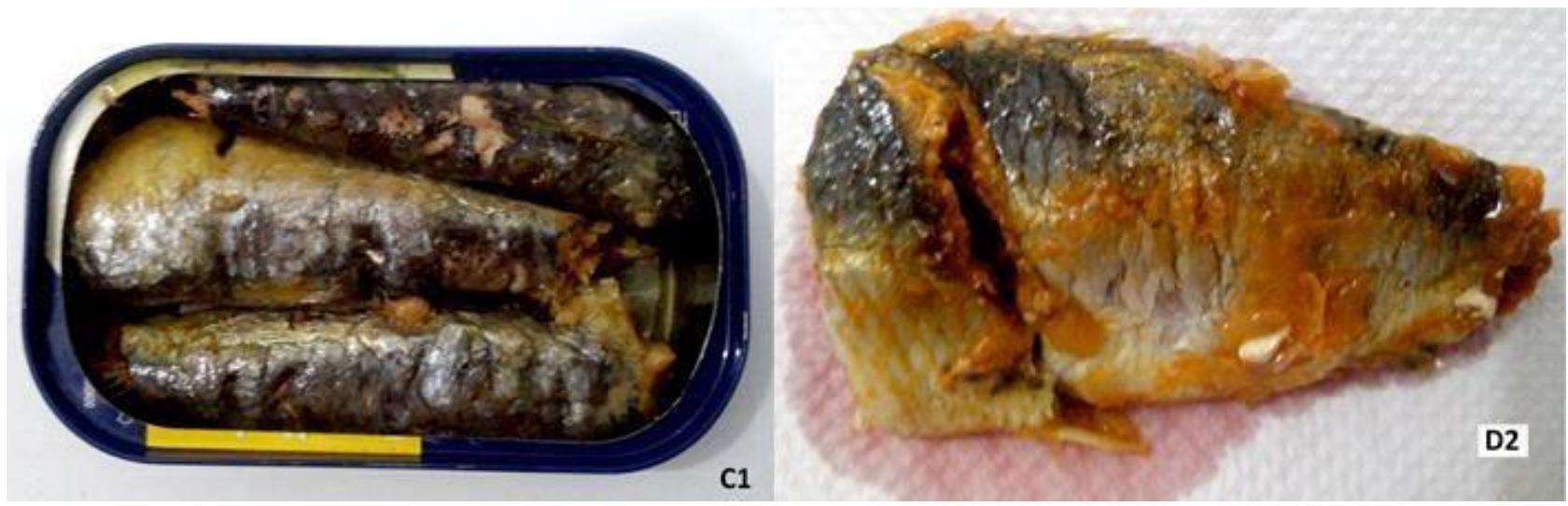

Figura 6. Lata com três peixes e com sinais de mutilação (Amostra C1) e peixe mutilado (Amostra D2) de sardinhas em conserva comercializadas na cidade de Aracaju, estado de Sergipe.

Todas as marcas, com exceção da marca $\mathrm{C}$ 1, apresentaram amostras com excesso de escamas soltas no fundo das latas, não estando em conformidade com o RITQ (Figura 7). 


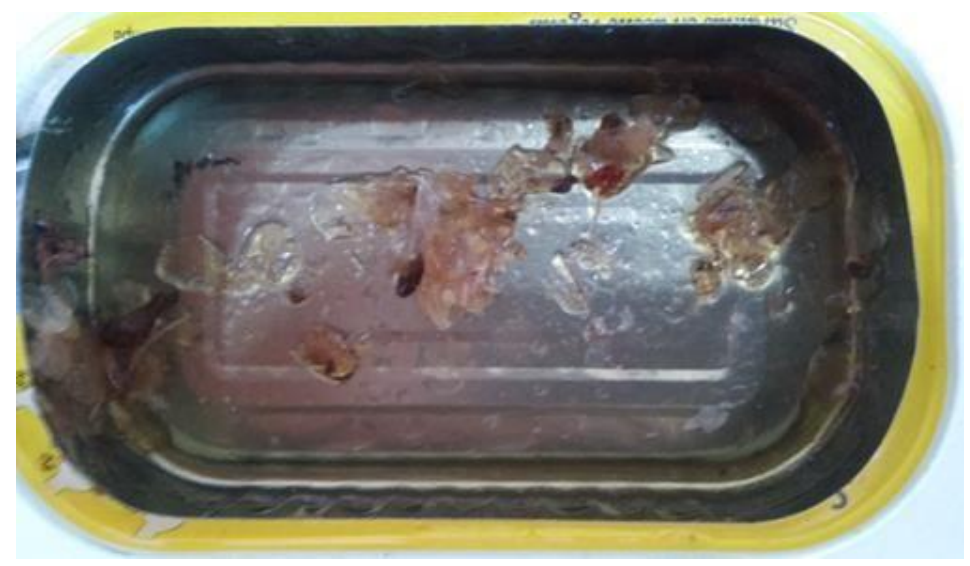

Figura 7. Lata com excesso de escamas soltas no fundo da lata (Amostra A1) de sardinhas em conserva comercializadas na cidade de Aracaju, estado de Sergipe.

Para o item Meio de cobertura (MC) foi observado que nenhuma das marcas apresentou coloração alterada referente ao indicado na rotulagem das mesmas e, portanto, na análise visual, estavam em conformidade com o RITQ.

Quanto à Qualidade da carne (QC), verificou-se que algumas amostras estavam em desacordo com o RTIQ por apresentarem carne com musculatura excessivamente mole e flácida. Semelhantemente ao que foi observado por Diniz et al. (2014), este experimento também verificou que para o item cor todas as marcas apresentaram percentuais maiores para a cor "Clara", o que demonstra estar de acordo com a Norma do Codex para as sardinhas e produtos análogos em conserva, (Codex Stan 94, 1981), que determina que a carne deve ser clara ou rosada, de consistência pouco fibrosa e não flácida ou esponjosa.

\section{ANÁliSE do PESO LÍQUidO (PL) DAS AMOSTRAS DE SARDINHAS EM CONSERVA}

De acordo com as definições de peso líquido (PL) e peso drenado (PD) constantes no Regulamento Técnico Metrológico, Portaria Inmetro no 157, de 19/08/02, chega-se à conclusão que a relação entre estas variáveis na análise de sardinhas em conserva pode ser expressa pela seguinte equação: PL $=$ PD + MC. Sendo que, de acordo com o RTIQ de conservas de sardinhas, no produto final, a carne (PD) deve constituir, no mínimo, 50\% (cinquenta por cento) em relação ao peso líquido declarado (PL).

Com relação ao peso líquido das sardinhas em óleo (Tabela 4), verificou-se que somente a marca C1, com $68 \%$ de PD, apresentou PL inferior ao declarado nas latas, no entanto esta tendência decorre da pouca quantidade do meio de cobertura empregado no enlatamento, já que a média dos pesos drenados manteve o mesmo padrão das outras marcas, chegando até mesmo a ser maior que a média dos pesos drenados da marca D1 (Tabela 3) que teve PL observado acima dos 125 gramas previstos, em virtude da utilização de uma maior quantidade de MC em relação ao peso líquido total. Para as demais marcas as médias dos PL foram superiores ao PL indicado nas latas.

Tabela 4. Análise do Peso líquido (PL) observado nas amostras de sardinhas em óleo, comercializadas na cidade de Aracaju-SE, estado de Sergipe.

\begin{tabular}{cccc}
\hline Sardinha em óleo & PL (g) Observado & PL (g) Declarado & Porcentagem de PD (g) \\
\hline A1 & $131,44 \pm 3,85$ & 125 & $71 \%$ \\
B1 & $127,76 \pm 3,24$ & 125 & $67 \%$ \\
C1 & $120,88 \pm 3,32$ & 125 & $68 \%$ \\
D1 & $126,24 \pm 4,32$ & 125 & $59 \%$ \\
E1 & $126,30 \pm 4,87$ & 125 & $67 \%$ \\
\hline
\end{tabular}


Para as sardinhas em molho de tomate (Tabela 5), verificou-se que somente a marca C2, com $75 \%$ de PD, apresentou PL inferior ao declarado nas latas (125g), cuja média foi de 116,6 gramas com desvio-padrão de \pm 2,15 gramas entre as latas. Tal medida de PL abaixo do valor especificado na rotulagem do produto, a exemplo do que ocorreu com a marca $\mathrm{C} 1$ para conservas em óleo, deve-se também à pouca quantidade do meio de cobertura empregado no enlatamento.

Tabela 5. Análise do Peso líquido (PL) observado nas amostras de sardinhas em molho de tomate, comercializadas na cidade de Aracaju, estado de Sergipe.

\begin{tabular}{cccc}
\hline $\begin{array}{c}\text { Sardinha em molho de } \\
\text { tomate }\end{array}$ & PL (g) Observado & PL (g) Declarado & Porcentagem de PD (g) \\
\hline A2 & $131,62 \pm 5,54$ & 125 & $67 \%$ \\
B2 & $128,00 \pm 3,04$ & 125 & $61 \%$ \\
C2 & $116,56 \pm 2,15$ & 125 & $75 \%$ \\
D2 & $128,06 \pm 1,95$ & 125 & $74 \%$ \\
E2 & $127,46 \pm 4,79$ & 125 & $70 \%$ \\
\hline
\end{tabular}

Como as médias de peso líquido das amostras das marcas C1 (sardinhas em óleo) e C2 (sardinhas em molho de tomate) foram as únicas a apresentarem valores inferiores ao valor declarado nas latas $(125 \mathrm{~g})$ e que esta alteração ocorreu devido à pouca quantidade de meio de cobertura utilizado, fica provado que esta falha decorre de um erro de processamento na indústria que produz essas duas marcas. A ocorrência de pouca quantidade MC em relação ao PL declarado pode ter sido ocasionada pelo espaço reduzido decorrente do enlatamento de três peixes por lata (Figura 6), ou então, devido às falhas de processamento como, por exemplo, a perda de MC na fase de aquecimento das latas para a formação do vácuo parcial.

\section{ANÁlise do PESo DRENADO (PD) DAS AMOSTRAS DE SARDINHAS EM ÓLEO COMESTÍvEL}

Com relação ao peso drenado médio observado e o declarado das marcas de sardinha em óleo (Tabela 6) verificou-se que todas as amostras da marca D1 apresentaram valores de PD observado abaixo do declarado nas latas. As demais marcas apresentaram valores tanto acima quanto do que foi declarado nas embalagens.

Tabela 6. Análise de variância (Anova) com significância estatística de 0,05 entre os Peso Drenado (PD) médio observado e declarado de sardinhas em óleo, comercializadas na cidade de Aracaju, estado de Sergipe.

\begin{tabular}{cccccc}
\hline $\begin{array}{c}\text { Sardinha } \\
\text { em óleo }\end{array}$ & PD (g) Observado & PD (g) Declarado & $F$ & valor- $P$ & F crítico \\
\hline A1 & $93,48 \pm 8,65$ & 83 & 7,34 & $0,03^{\mathrm{DS}}$ & 5,32 \\
B1 & $85,16 \pm 13,97$ & 84 & 0,03 & $0,86^{\mathrm{NDS}}$ & 5,32 \\
C1 & $82,28 \pm 11,10$ & 84 & 0,12 & $0,74^{\mathrm{NDS}}$ & 5,32 \\
D1 & $74,64 \pm 4,03$ & 84 & 26,99 & $0,0008^{\mathrm{DS}}$ & 5,32 \\
E1 & $84,3 \pm 9,38$ & 83 & 0,10 & $0,76^{\mathrm{NDS}}$ & 5,32 \\
\hline
\end{tabular}

DS - difere significamente em relação ao PD declarado na embalagem.

NDS - não difere significamente em relação ao PD declarado na embalagem.

Nota-se também, que a marca B1 foi a que apresentou PD médio mais próximo do peso declarado.

A análise de variância (Anova) mostrou que as marcas A1 e D1 foram as que apresentaram diferença significativa em relação ao PD declarado nas suas respectivas latas, sendo que a quantidade de carne de D1 ficou abaixo do indicado na embalagem em todas as amostras. As médias das demais marcas foram consideradas estatisticamente semelhantes ao PD declarado. 


\section{ANÁLISE Do PESo DRENADO (PD) DAS AMOSTRAS DE SARDINHAS EM MOLHO DE TOMATE}

O teste Anova (tabela 7) concluiu que somente a marca D2 apresentou diferença significativa entre as médias do PD observado e do PD declarado, com média de peso drenado bem superior ao que foi declarado nas latas. As demais marcas foram consideradas com conteúdo sólido estatisticamente semelhantes ao PD declarado.

Observou-se também que a marca B2, com desvio-padrão de $\pm 10,35$ gramas, foi a única que apresentou PD médio inferior ao declarado.

Tabela 7. Análise de variância (Anova) com significância estatística de 0,05 entre os Peso Drenado (PD) médio observado e declarado de sardinhas em molho de tomate, comercializadas na cidade de Aracaju, estado de Sergipe.

\begin{tabular}{clcccc}
\hline $\begin{array}{c}\text { Sardinha } \\
\text { em molho de tomate }\end{array}$ & PD $(\mathrm{g})$ Observado & PD $(\mathrm{g})$ Declarado & $F$ & valor- $P$ & F crítico \\
\hline A2 & $88,66 \pm 8,72$ & 83 & 2,11 & $0,18^{\mathrm{NDS}}$ & 5,32 \\
B2 & $78,60 \pm 10,35$ & 84 & 1,36 & $0,28^{\mathrm{NDS}}$ & 5,32 \\
C2 & $87,08 \pm 4,45$ & 84 & 2,39 & $0,16^{\mathrm{NDS}}$ & 5,32 \\
D2 & $94,66 \pm 5,37$ & 84 & 19,71 & $0,002^{\mathrm{DS}}$ & 5,32 \\
E2 & $89,66 \pm 9,10$ & 83 & 2,68 & $0,14^{\mathrm{NDS}}$ & 5,32 \\
\hline
\end{tabular}

DS - difere significamente em relação ao PD declarado na embalagem.

NDS - não difere significamente em relação ao PD declarado na embalagem.

Resultados semelhantes foram encontrados nos trabalhos de Barbosa et al. (2006) e Diniz et al. (2014), que observaram valores de PD superiores e inferiores aos declarados nas latas de algumas das marcas analisadas.

\section{ANÁLISE SENSORIAL DE SARDINHAS EM ÓLEO COMESTÍVEL}

O gráfico da Figura 8 mostra que, dentre as marcas de sardinha em óleo, as marcas D1 e E1 foram as que apresentaram maior índice de aceitação e que a marca B1 foi a mais rejeitada.

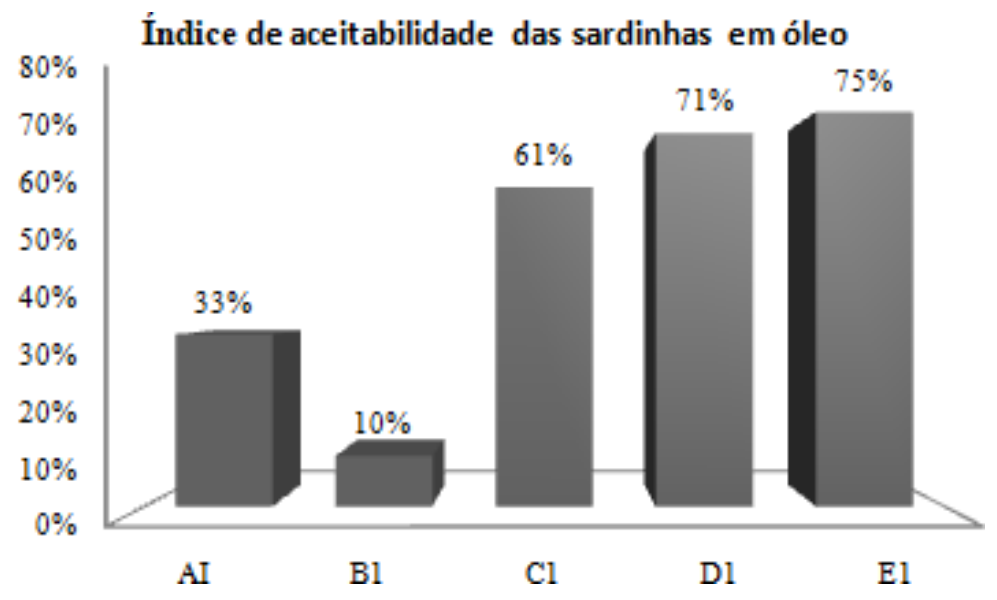

Figura 8. Índice de aceitabilidade de sardinhas em conserva em óleo, comercializadas na cidade de Aracaju, estado de Sergipe.

Da análise sensorial de aceitação em todos os atributos avaliados para as marcas de sardinha em óleo (Tabela 8), constatou-se que as marcas melhores avaliadas (D1 e E1), não apresentaram diferença significativa ( $\mathrm{p}>0,05)$, obtendo médias próximas a $4(4=\mathrm{Boa})$, mostrando que os provadores avaliaram que ambas mostraram as maiores notas para os atributos analisados e que possuem características sensoriais semelhantes. Enquanto que a marca B1 apresentou diferença significativa $(\mathrm{p}<0,05)$ em relação as marcas D1 e E1 em todos os atributos, sendo reprovada pelos avaliadores por apresentar médias próximas de 1 ( $1=$ Ruim). 
Tabela 8. Médias de aceitação em relação à aparência, cor, odor, sabor e textura das amostras de sardinhas em óleo, comercializadas na cidade de Aracaju, estado de Sergipe.

\begin{tabular}{cccccc}
\hline $\begin{array}{c}\text { Sardinhas } \\
\text { em óleo }\end{array}$ & Aparência & Cor & Odor & Sabor & Textura \\
\hline A1 & $3,0 \pm 1,2^{\mathrm{a}}$ & $3,0 \pm 1,4^{\mathrm{a}}$ & $2,3 \pm 1,3^{\mathrm{a}}$ & $1,8 \pm 1,5^{\mathrm{a}}$ & $2,8 \pm 1,5^{\mathrm{a}}$ \\
B1 & $2,0 \pm 1,3^{\mathrm{a}}$ & $1,6 \pm 1,1^{\mathrm{a}}$ & $1,8 \pm 1,2^{\mathrm{a}}$ & $1,6 \pm 0,8^{\mathrm{ab}}$ & $1,5 \pm 1,1^{\mathrm{a}}$ \\
C1 & $3,8 \pm 1,1^{\mathrm{ab}}$ & $3,6 \pm 1,2^{\mathrm{ab}}$ & $4,0 \pm 1,2^{\mathrm{b}}$ & $3,2 \pm 1,7^{\mathrm{abc}}$ & $3,3 \pm 1,4^{\mathrm{ab}}$ \\
D1 & $4,4 \pm 0,5^{\mathrm{bc}}$ & $3,8 \pm 1,0^{\mathrm{abc}}$ & $3,6 \pm 0,7^{\mathrm{abc}}$ & $3,6 \pm 1,2^{\mathrm{cd}}$ & $4,1 \pm 0,9^{\mathrm{abc}}$ \\
E1 & $4,2 \pm 0,6^{\mathrm{abc}}$ & $4,1 \pm 0,9^{\mathrm{abc}}$ & $4,1 \pm 1,0^{\mathrm{bc}}$ & $4,0 \pm 1,2^{\mathrm{cd}}$ & $4,0 \pm 0,8^{\mathrm{abc}}$ \\
\hline
\end{tabular}

Médias seguidas pelas mesmas letras nas colunas não diferem entre si pelo Teste de Tukey $(\mathrm{p} \leq 0,05)$.

Escala: 1 = ruim; 5 = muito bom

\section{ANÁLISE SENSORIAL DE SARDINHAS EM MOLHO DE TOMATE}

Pelos resultados obtidos no gráfico abaixo, verifica-se que a marca $\mathrm{C} 2$ foi a mais aceita pelos provadores, enquanto que a marca B2 foi a mais rejeitada.

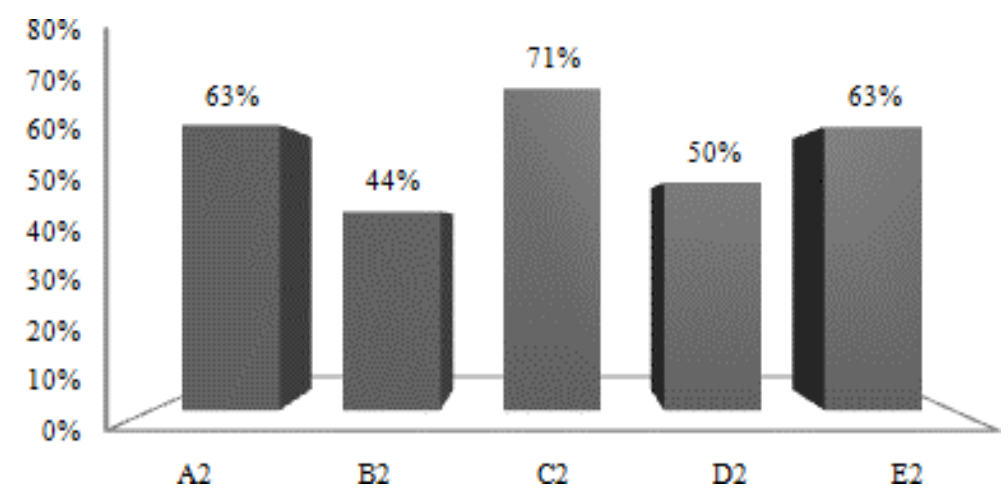

Figura 9. Índice de aceitabilidade de sardinhas em conserva em molho de tomate, comercializadas na cidade de Aracaju, estado de Sergipe.

O Teste de Tukey $(\mathrm{p} \leq 0,05)$ aplicado nos valores encontrados para as sardinhas de molho de tomate (Tabela 9), mostrou que não existe diferença significativa $(\mathrm{p}>0,05)$ entre a marca melhor avaliada $(\mathrm{C} 2=71 \%$ de aceitação) e as marcas A2 e E2 (ambas com 63\% de aceitabilidade). Como todas elas apresentaram médias próximas a $4(4=$ Boa $)$, os provadores avaliaram que ambas são bem aceitas e que possuem características sensoriais semelhantes.

Tabela 9. Médias de aceitação em relação à aparência, cor, odor, sabor e textura das amostras de sardinhas em molho de tomate, comercializadas na cidade de Aracaju, estado de Sergipe.

\begin{tabular}{cccccc}
\hline $\begin{array}{c}\text { Sardinhas } \\
\text { em óleo }\end{array}$ & Aparência & Cor & Odor & Sabor & Textura \\
\hline A2 & $3,9 \pm 0,9^{\mathrm{a}}$ & $4,1 \pm 0,6^{\mathrm{a}}$ & $3,8 \pm 1,0^{\mathrm{a}}$ & $2,8 \pm 1,4^{\mathrm{a}}$ & $3,9 \pm 1,1^{\mathrm{a}}$ \\
B2 & $3,3 \pm 1,2^{\mathrm{a}}$ & $3,8 \pm 1,0^{\mathrm{a}}$ & $2,6 \pm 1,5^{\mathrm{a}}$ & $2,0 \pm 1,2^{\mathrm{ab}}$ & $2,8 \pm 1,4^{\mathrm{a}}$ \\
C2 & $4,4 \pm 0,5^{\mathrm{a}}$ & $3,7 \pm 1,3^{\mathrm{a}}$ & $3,5 \pm 1,3^{\mathrm{a}}$ & $3,6 \pm 1,5^{\mathrm{abc}}$ & $4,0 \pm 1,2^{\mathrm{a}}$ \\
D2 & $3,8 \pm 0,9^{\mathrm{a}}$ & $3,8 \pm 0,8^{\mathrm{a}}$ & $3,8 \pm 0,8^{\mathrm{a}}$ & $1,8 \pm 1,1^{\mathrm{ab}}$ & $3,5 \pm 1,0^{\mathrm{a}}$ \\
E2 & $3,2 \pm 1,3^{\mathrm{a}}$ & $3,8 \pm 1,1^{\mathrm{a}}$ & $3,8 \pm 1,1^{\mathrm{a}}$ & $3,9 \pm 1,1^{\mathrm{ac}}$ & $4,0 \pm 0,8^{\mathrm{a}}$ \\
\hline
\end{tabular}

Médias seguidas pelas mesmas letras nas colunas não diferem entre si pelo Teste de Tukey $(\mathrm{p} \leq 0,05)$.

Escala: $1=$ ruim; 5 = muitobom 
Constatou-se, também, que para os atributos "Aparência", "Cor", "Odor" e "Textura" as marcas B2 e D2, que tiveram os menores desempenhos no índice de aceitabilidade, não apresentarem diferença significativa em relação às demais marcas. Porém, apresentaram médias próximas a $2(2=$ Regular $)$ para o aspecto "Sabor".

\section{Conclusão}

Apesar de serem encontrados defeitos, quando da aplicação do Regulamento Técnico de Identidade e Qualidade de Conservas de Sardinhas, de modo geral, as sardinhas analisadas podem ser consideradas de boa qualidade e adequadas para o consumo. No entanto, na busca pela melhoria contínua, faz-se necessário que as medidas de controle de qualidade das marcas estudadas sejam cada vez mais efetivas, a fim de assegurar produtos de melhor qualidade para o consumidor que a cada dia é mais exigente.

\section{Referências}

Aubourg, S. (2001). Review: Loss of quality during the manufacture of canned fish products. Food Science and Technology International, 7, 199-215.

Barbosa, J.M., Queiroz, D.M., Santos, E.C.B., Mendes, P.P. \& Leitão, S.S. (2006). Avaliação de sardinhas em conserva, comercializadas na cidade do Recife, Pernambuco. Revista Higiene Alimentar, 20 (138): 53-55.

Brasil (1952). Regulamento da inspeção industrial e sanitária de produtos de origem animal. Riispoa. Rio de Janeiro: Decreto no 30.691, de 29/03/52.

Brasil (1997). Regulamento Técnico de Identidade e Qualidade de Peixe Fresco (Inteiro e Eviscerado). Brasília: Ministério da Agricultura e do Abastecimento. Portaria no 185, de 13/05/97.

Brasil (2000a). Regulamento Técnico Metrológico - Critérios para Verificação do Conteúdo Líquido de Produtos Pré-medidos. Brasília: Ministério do Desenvolvimento, Indústria e Comércio Exterior. Portaria Inmetro $\mathrm{n}^{\mathrm{O}} 248$ de 17/07/08.

Brasil (2000b). Regulamento Técnico Metrológico - Metodologia para Determinação do Peso Drenado para os Produtos Pré-medidos. Brasília: Ministério da Indústria, do Comércio e do Turismo. Portaria Inmetro $\mathrm{n}^{\mathrm{o}} 231$, de 19/09/00.

Brasil (2002). Regulamento Técnico Metrológico - Forma de Expressar Conteúdo Líquido a Ser Utilizado nos Produtos pré-medidos. Brasília:Ministério da Indústria, do Comércio e do Turismo. Portaria Inmetro no ${ }^{157}$, de $19 / 08 / 02$.

Brasil (2005). Regulamento Técnico para Rotulagem de Produto de Origem Animal Embalado. Brasília: Ministério da Agricultura Pecuária e Abastecimento. Instrução Normativa no 22, de 24/11/05.

Brasil (2010). Regulamento Técnico de Identidade e Qualidade de Conservas de Sardinhas. Brasília: Ministério da Agricultura Pecuária e Abastecimento, Secretaria de Defesa Agropecuária. Portaria no 406, de 10 de agosto de 2010.

Brasil (2011a). Regulamento Técnico que Fixa a Identidade e as Características Mínimas de Qualidade que Deve Apresentar o Produto Conservas de Sardinhas para a Sua Comercialização. Brasília: Ministério da Agricultura Pecuária e Abastecimento. Instrução Normativa SDA n²2, de 11/07/11.

Brasil (2011b). Regulamento Técnico de Identidade e Qualidade de Conservas de Peixes. Ministério da Agricultura Pecuária e Abastecimento. Instrução Normativa SDA no 45, de 13/12/11.

Braz, N., Monraia, C., Loja, F., Ribeiro, J, \& Garcez, M.G. (2006). Código de Boas Práticas das conservas de sardinha e do tipo de sardinha. Lisboa: Alif - Associação da Indústria Alimentar pelo Frio.

Chagas, V.R.S., Gaspar, A., Ramos, G.D.M., Santos, R.R. \& Paula, L.C. (2010). Qualidade física e química de sardinhas em pré e pós processamento. Rev. Ciências da Vida, 30 (2): 35-36.

Codex Stan 119 (1981). Codex standard for canned finfish. Roma: FAO.

Codex Stan 94 (1981). Codex standard for canned sardines and sardine-type products. Roma: FAO.

Costa, L. (2011). A história do enlatamento de alimentos. Acessado em 26 de outubro de 2015 emhttp://stravaganzastravaganza.blogspot.com.br/2011/03/historia-do-enlatamento-de-alimentos.html.

Diniz, T.D., Barbosa, J.M. \& Santos, E.C.B. (2014). Qualidade de sardinhas em conserva comercializadas em São Luís, Estado do Maranhão. Rev. Sodebras, 9 (108): 24-28.

Figueiredo, J.L. \& Menezes, N.A. (1978). Manual de peixes marinhos do sudeste do Brasil. II. Teleostei (1). São Paulo: Museu de Zoologia da Universidade de São Paulo.

Franco, B.D.G.M. \& Landgraf, M. (2005). Microbiologia de alimentos. São Paulo: Atheneu.

Gava, A. J. (1998). Embalagens para alimentos. In: Gava, A. J. Princípios de tecnologia de alimentos (pp. 105-118). São Paulo: Ed. Nobel. 
Gonçalves, A.A. (2004). Aproveitamento integral da tilápia no processamento. In: Sociedade Brasileira de Aquicultura e Biologia Aquática. (Org.). Aquaciência 2004: Tópicos Especiais em Biologia Aquática e Aquicultura (pp. 237-259). Jaboticabal: Sociedade Brasileira de Aqüicultura e Biologia Aquática.

Lima, L.C., Dell'Isola, A.T.P. \&Schettin, M.A. (2000). Processamento Artesanal de Pescado. Viçosa: CPT.

Ogawa, M. \& Maia, E.L. (1999). Manual de pesca. São Paulo: Varela, 430p.

Teixeira, L.V. (2009). Análise Sensorial na Indústria de Alimentos. Rev. Inst. Latic. Cândido Tostes, 366 (64): $12-21$.

Vasconcelos, M.A.S. \& Melo-Filho, A.B. (2010). Conservação de alimentos pelo calor. In: Melo Filho, A.B \& Vasconcelos, M.A.S. Conservação de alimentos (pp. 23-36). Recife (PE): Edufrpe. 